\title{
Tailored Cigarette Warning Messages: How Individualized Loss Aversion and Delay Discounting Rates Can Influence Perceived Message Effectiveness
}

\author{
Hollie L. Tripp ${ }^{1, *}$, Justin C. Strickland ${ }^{2}$, Melissa Mercincavage ${ }^{1}$, Janet Audrain-McGovern ${ }^{1}$, Eric C. Donny ${ }^{3}$ \\ and Andrew A. Strasser ${ }^{1}$ \\ 1 Department of Psychiatry, Perelman School of Medicine, University of Pennsylvania, \\ Philadelphia, PA 19104, USA; melmer@pennmedicine.upenn.edu (M.M.); \\ audrain@pennmedicine.upenn.edu (J.A.-M.); strasse3@pennmedicine.upenn.edu (A.A.S.) \\ 2 Department of Psychiatry and Behavioral Sciences, School of Medicine, Johns Hopkins University, \\ Baltimore, MD 21224, USA; jstric14@jhmi.edu \\ 3 Department of Physiology and Pharmacology, Wake Forest School of Medicine, \\ Winston-Salem, NC 27157, USA; edonny@wakehealth.edu \\ * Correspondence: htripp@fandm.edu
}

Citation: Tripp, H.L.; Strickland, J.C.; Mercincavage, M.; AudrainMcGovern, J.; Donny, E.C.; Strasser, A.A. Tailored Cigarette Warning Messages: How Individualized Loss Aversion and Delay Discounting Rates Can Influence Perceived Message Effectiveness. Int. J. Environ. Res. Public Health 2021, 18, 10492. https://doi.org/10.3390/ ijerph181910492

Academic Editors: Elizabeth G. Klein, Amanda Quisenberry and Michael Chaiton

Received: 16 August 2021

Accepted: 1 October 2021

Published: 6 October 2021

Publisher's Note: MDPI stays neutral with regard to jurisdictional claims in published maps and institutional affiliations.

Copyright: (c) 2021 by the authors. Licensee MDPI, Basel, Switzerland. This article is an open access article distributed under the terms and conditions of the Creative Commons Attribution (CC BY) license (https:// creativecommons.org/licenses/by/ $4.0 /)$.

\begin{abstract}
Current text-only cigarette warning labels (long-term, loss-framed messages) may not motivate positive changes in smoking behavior. The current project was a cross-sectional study examining the effects of tailored cigarette warnings on perceived message effectiveness (PME) in adult smokers $(n=512)$ conducted using Amazon Mechanical Turk (M-Turk) in January-February 2020. Participants were an average age of 40.7 (SD = 11.6), with the majority of the sample being female $(62.2 \%)$ and White (88.9\%). Participants reported smoking an average of 14.6 cigarettes/day $(\mathrm{SD}=9.2)$ with an average FTND score of $4.6(\mathrm{SD}=2.2)$. Participants were asked to complete a tobacco use history questionnaire, and mixed gambles and delay discounting tasks before random assignment to one of five message groups. The groups were based on a 2 (gain versus loss framing) $\times 2$ (short-term versus long-term framing) between-subject design; a fifth group served as the control group. All experimental messages reported higher PME scores than the control ( $p$ values $<0.001$, Cohen's $d=1.88-2.48$ ). Participants with shallower delayed reward discounting and lower loss aversion rates reported higher total PME scores, $p$ values $<0.05$. Our findings also suggest that loss aversion rates vary widely among smokers and that individuals are more responsive to messages congruent with their behavioral economic profile. Specifically, smokers who viewed messages congruent with their loss aversion and delay discounting rates reported higher PME scores than those who viewed incongruent messages $(p=0.04$, Cohen's $d=0.24)$. These preliminary findings suggest that anti-smoking campaigns may best impact smokers by tailoring messages based on individual loss aversion and delay discounting rates versus a one-size-fits-all approach.
\end{abstract}

Keywords: loss aversion; framing; cigarette warning messages; delay discounting; perceived message effectiveness

\section{Introduction}

In 1965, Congress passed the Federal Cigarette Labeling and Advertising Act, requiring that cigarette packaging have text warning labels alerting consumers of the potential negative health consequences of smoking. In 1981, additional warnings with more descriptive text were added to the initial caution message. Since then, researchers have examined how the manipulation of text warning label size, color, placement, and congruency with images influences smokers' decision making [1-4].

Prospect theory has been used to conceptualize how cigarette-related health messages influence risky decision making. Prospect theory presents two primary changes to previous decision-making theories directly relevant to risk messaging: framing and loss aversion [5]. 
Specifically, when presented with a decision, individuals' choices are influenced by whether the outcome was conveyed as a potential gain or loss (i.e., framing), and whether people are more sensitive to the prospect of a loss than a gain (i.e., loss aversion) [6-9]. Many studies have examined the influence of gain and loss messaging on the behaviors of cigarette smokers. Some studies have found greater intentions to quit or changes in attitudes towards smoking cessation for participants exposed to gain-framed messaging [10-13]. These studies suggest that gain-framed messages are better received when individuals are trying to prevent the occurrence of disease, as is the case with smoking. However, other studies have found loss-framed messages to be more effective than gain-framed messages at increasing intentions to quit among smokers, in smokers with high self-efficacy, or for smokers simultaneously exposed to graphic warning labels [14-16]. One study found that utilizing both types of frames within a contingency management program was effective but led to different outcomes; individuals exposed to loss-framed incentives were more likely to initiate cessation and gain-framed incentives were more likely to maintain cessation [17]. However, none of these studies were conducted with consideration that loss aversion rates-measures of sensitivity to prospective losses compared to prospective gains-may vary. Based on the pattern of results in the existing literature, it is plausible that individual variation in loss sensitivity may help to understand the interaction of message type and individual or smoking group. If an individual is not loss averse, they may find loss-framed messages less compelling than someone who is loss averse.

The temporal context is another feature of framing that can influence perceptions of anti-smoking messages and warnings $[18,19]$. Delay discounting describes the devaluation of an outcome by the delay to its occurrence, often resulting in a preference for a shortterm outcome over a long-term (but more desirable) outcome [20-22]. Cigarette warning labels often present distal health consequences of tobacco use, mitigating the urgency to quit smoking because of the devaluation of those future consequences [23-25]. It follows that those who discount the future more steeply may respond to messages with short-term framing more readily than messages with long-term framing. For example, an individual with a high delay discount rate may not be as concerned by a message indicating that they may develop lung cancer later in life as someone who discounts future health outcomes less.

Some studies have simultaneously examined the delay (short-term versus long-term) and sign (gain versus loss-framing) of cigarette warning labels [16,26]. One study found that gain messages improved intention-to-quit rates over loss messages, particularly for messages that expressed short-term outcomes [26]. However, another study found loss messages to have a greater impact on perceived effectiveness than gain messages, and no difference between short- and long-term messages [16]. The reason for mixed findings regarding the optimal message framing and temporal context to influence smokers' perceptions may be because these studies did not consider how individual differences in loss aversion and/or delay discounting may influence a person's perceptions of and reaction to these messages. This may be especially true of people who use drugs, for whom the evidence suggests lower levels of loss aversion and higher delay discounting rates than healthy populations [27-30]. Therefore, long-term, loss-focused cigarette warning labels may be less effective for influencing smokers than posited, and substantial individual variability may exist in the effectiveness of messages.

This randomized experimental study aims to evaluate the interaction between the framing of messages and person-specific behavioral economic characteristics. Specifically, the study frames anti-smoking messages by temporal context (long-term or short-term) and sign (gain or loss) and then examines whether individual loss aversion and delay discounting rates influence perceived message effectiveness.

The findings may optimize the communication of public health warnings to targeted audiences. 


\section{Materials and Methods}

\subsection{Sample}

Participants were recruited from the crowdsourcing website Amazon Mechanical Turk (MTurk). A brief description of the survey was posted to the MTurk forum. The description was visible only to those who resided in the United States, had an approval rating of at least $99 \%$, had completed at least 100 MTurk tasks, were at least 18 years of age, and had not already completed this survey. The task description did not indicate that this survey was about tobacco use, to minimize potential bias in responses to questions related to inclusion criteria. Interested individuals clicked on the Qaultrics link for the pre-screening survey, where CAPTCHA was used to prevent data entry by bots. Participants then accepted consent language before completing the one-minute screener survey to determine if they were eligible by being a current, daily smoker (i.e., had smoked 28 out of the past 30 days). Those who were eligible were invited to complete the full survey. The survey consisted of tobacco use questions, loss aversion and delay discounting tasks completed via PsyToolKit, message exposure, questions regarding perceived message effectiveness, and demographic questions [31]. The full survey lasted approximately $17 \mathrm{~min}$ and participants were compensated with USD 1.75 via their MTurk account (USD 0.05 for the screener and USD 1.70 for the full survey). MTurk user IDs were tracked to ensure that individuals only participated once. At the end of the survey, participants were told that the messages were not approved by the FDA and were then provided with resources to help them quit smoking. This protocol (834419) was reviewed and considered exempted by the University of Pennsylvania IRB.

\subsection{Data Collection}

\subsubsection{Tobacco Use and Demographic Questions}

Participants were asked to answer tobacco use and demographic questions. Tobacco use questions included those from the Fagerstrom Test for Nicotine Dependence (FTND) [32]. Participants were also asked "If you decided to give up smoking completing in the next 6 months, how sure are you that you would succeed" in order to gauge self-efficacy of smoking cessation ( $1=$ "not at all sure" to $4=$ "extremely sure"). Demographic questions asked participants for information regarding their gender, race, ethnicity, education, income, sexual orientation, employment status, marital status, and their state of residence.

\subsubsection{Behavioral Economic Tasks}

Two behavioral economic tasks were included (1) a mixed gambles task to assess loss aversion and (2) a 5-choice discounting task to assess gain and loss delay discounting. Loss aversion and delay discounting tasks were completed in a randomized order prior to message exposure.

Participants indicated whether they would accept or reject gambles with equal odds of winning or losing hypothetical amounts of money in the mixed gambles task [33,34]. Delay discounting was assessed using the 5-trial adjusting delay discounting task [35]. In this discounting task, participants were presented with an amount of hypothetical money and asked if they preferred that amount in three weeks or half the amount now. Each of the subsequent four trials repeated this discrete choice question, but with titration up or down conditional on the previous response. Delay discounting was assessed for delayed gains and losses of USD 1000.

\subsubsection{Message Delivery}

After completing the behavioral economic procedures, participants were randomly assigned to one of five message groups. The groups were based on a 2 (gain versus loss framing) $\times 2$ (short-term versus long-term framing) between-subject design. A fifth group was included as a control condition in which participants were exposed to a message about television use; the use of an anti-smoking warning for the control message would not have been entirely separate from all other conditions given that warnings convey 
consequences (present or future) which must be conveyed as a potential loss or gain. In each experimental message group, participants were exposed to three messages (health, cost, and aesthetics, respectively) that represented one of the four experimental conditions or the control condition. Those messages are visible in Table 1. Long-term messages indicate more severe consequences than short-term messages because risks increase the longer an individual smokes cigarettes.

Table 1. Exposure group messages with health, cost, and aesthetic outcomes.

\begin{tabular}{ll}
\hline \multirow{2}{*}{ Exposure 1: Long-Term Gains } & If you quit smoking cigarettes, you could add 10 years to your life. \\
& $\begin{array}{l}\text { If you quit smoking cigarettes, your skin could look better for longer. } \\
\text { If you quit smoking cigarettes, you could save thousands of dollars over } 10 \text { years. }\end{array}$ \\
& $\begin{array}{l}\text { If you continue smoking cigarettes, you could cut up to } 10 \text { years off of your life. } \\
\text { Exposure 2: Long-Term Losses }\end{array}$ \\
$\begin{array}{l}\text { If you continue smoking cigarettes, you could age prematurely. } \\
\text { If you continue smoking cigarettes, you could spend thousands of dollars } \\
\text { over } 10 \text { years. }\end{array}$
\end{tabular}

If you quit smoking cigarettes, your breathing could improve in a month.

Exposure 3: Short-Term Gains If you quit smoking cigarettes, you wouldn't smell like smoke.

If you quit smoking cigarettes, you could immediately have more money for other things you enjoy.

If you continue smoking cigarettes, you could have trouble climbing stairs this month.

Exposure 4: Short-Term Losses If you continue smoking cigarettes, you could smell like smoke. If you continue smoking cigarettes, you are spending money that you could be using right now on other things you enjoy.

Watching several hours of television could affect your health.

Exposure Control: Hours of Watching Television There is a correlation between the number of hours that one watches television and one's body fat mass.

Time watching television could influence how you see the world.

\subsubsection{Perceived Message Effectiveness}

After exposure to the randomly assigned messages, participants were asked to respond to three statements related to perceived message effectiveness (PME) using the University of North Carolina's PME scale [36]. Responses to each statement ranged from strongly disagree (1) to strongly agree (5). The three statements from UNC's PME scale were: “This message discourages me from wanting to smoke", "This message makes me concerned about the health effects of smoking," and "This message makes smoking seem unpleasant to me". Scores were summed for a total PME score variable.

\subsection{Data Analysis}

Descriptive statistics were first used to summarize study variables in the total sample and by randomized message type. Total PME scores were then evaluated first within the total sample using a one-way ANOVA with message type as the between-subject factor. Total PME scores were then evaluated within active message conditions using a $2 \times 2$ ANOVA with delay (short-term versus long-term framing) and sign (gain versus loss framing) as between-subject factors. Supplemental analyses also evaluated individual PME scores using this approach.

Individual difference predictors of PME response were evaluated using multiple regression within active message conditions. Demographic, tobacco use, and behavioral economic variables were included as predictors of PME total scores. Message type was also included in this model as two dummy-coded variables; (1) delay (long-term or short-term messages) and (2) sign (loss or gain related messages). Additional tests were conducted predicting individual PME items using this same approach. Similar results for these individual items were observed when analyzed using ordinal logistic regression models 
(Supplemental Table S1). Therefore, results are presented here for the linear regression models for conceptual simplicity and correspondence with total score analyses.

The impact of message exposure paired with behavioral economic variables was evaluated using median splits (defined as low versus high) on delayed rewarded discounting, delayed loss discounting, and loss aversion variables. Specifically, participants were considered congruent if these behavioral economics measures corresponded to those desirable for their randomized message condition (Table 2). A categorical rather than continuous split was used to relax a more rigid assumption of a linear impact of these behavioral economic matching variables on PME response. Sensitivity tests were also conducted considering congruency exclusively based on delay discounting or loss aversion variables rather than their combination. Analyses were conducted in $R$ Statistical Analysis (R Foundation for Statistical Computing, Vienna, Austria) and JASP [37] using two-tailed tests and a type I error rate of 0.05 . Effect sizes for pairwise comparisons are summarized using the effect size measure Cohen's $d$.

Table 2. Congruent messaging given delay discounting and loss aversion rates.

\begin{tabular}{clcc}
\hline Variable & \multicolumn{3}{c}{ Loss Aversion Coefficient } \\
\hline \multirow{3}{*}{ Delay Discounting Rate } & High Sensitivity to Loss & Low Sensitivity to Loss \\
\cline { 2 - 4 } & High Discounting Rate & Short-term, loss message & Short-term, gain message \\
\cline { 2 - 4 } & Low Discounting Rate & Long-term, loss message & Long-term, gain message \\
\hline
\end{tabular}

\section{Results}

\subsection{Sample Characteristics}

Overall, participants $(n=512)$ were an average age of $40.7(\mathrm{SD}=11.6)$, with a majority of the sample being female $(62.2 \%)$ and White $(88.9 \%)$. Participants reported smoking an average of 14.6 cigarettes/day $(\mathrm{SD}=9.2)$ with an average FTND score of $4.6(\mathrm{SD}=2.2)$. Table 3 contains demographic, tobacco use, and behavioral economic variables for the study sample separated by randomized message type. No significant group differences were observed for these variables, $p$ values $>0.05$.

Table 3. Demographic, substance use, and behavioral economic variables by message assignment.

\begin{tabular}{|c|c|c|c|c|c|}
\hline \multirow{2}{*}{ Variable } & $\begin{array}{l}\text { Control } \\
(n=101)\end{array}$ & $\begin{array}{l}\text { Long-Term Gain } \\
\qquad(n=102)\end{array}$ & $\begin{array}{l}\text { Long-Term Loss } \\
\qquad(n=103)\end{array}$ & $\begin{array}{l}\text { Short-Term Gain } \\
\qquad(n=102)\end{array}$ & $\begin{array}{l}\text { Short-Term Loss } \\
\quad(n=104)\end{array}$ \\
\hline & Mean (SD)/\% & Mean (SD)/\% & Mean (SD)/\% & Mean (SD)/\% & Mean (SD)/\% \\
\hline \multicolumn{6}{|l|}{ Demographic } \\
\hline Age & $39.9(11.1)$ & $41.6(12.5)$ & $41.5(11.2)$ & $40.0(11.4)$ & 40.7 (11.9) \\
\hline Female & $69.3 \%$ & $57.8 \%$ & $55.9 \%$ & $61.4 \%$ & $66.4 \%$ \\
\hline Married & $50.5 \%$ & $52.0 \%$ & $48.5 \%$ & $46.1 \%$ & $51.0 \%$ \\
\hline White & $90.1 \%$ & $89.2 \%$ & $89.3 \%$ & $87.3 \%$ & $88.5 \%$ \\
\hline College Education & $46.5 \%$ & $45.1 \%$ & $46.6 \%$ & $52.0 \%$ & $45.2 \%$ \\
\hline Income $^{a}$ & $4.1(1.8)$ & $3.9(1.8)$ & $3.9(1.7)$ & $3.8(1.8)$ & $3.9(1.9)$ \\
\hline \multicolumn{6}{|l|}{ Substance Use } \\
\hline Past Month Vaping & $43.6 \%$ & $43.1 \%$ & $41.8 \%$ & $42.2 \%$ & $41.4 \%$ \\
\hline Cigarettes/Day & $14.2(6.6)$ & $14.9(7.7)$ & $15.2(9.6)$ & $14.7(13.1)$ & $14.1(7.6)$ \\
\hline FTND & $4.4(2.1)$ & $4.7(2.1)$ & $4.7(2.2)$ & $4.5(2.4)$ & $4.8(2.2)$ \\
\hline Perceived Quit Efficacy b & $0.8(0.9)$ & $0.9(1)$ & $0.8(0.8)$ & $0.7(0.8)$ & $0.8(0.9)$ \\
\hline \multicolumn{6}{|l|}{ Behavioral Economic } \\
\hline Gain Discounting (Log) & $-2.4(0.8)$ & $-2.3(0.8)$ & $-2.4(0.7)$ & $-2.1(0.9)$ & $-2.3(0.9)$ \\
\hline Loss Discounting (Log) & $-2.7(1.2)$ & $-2.7(1.1)$ & $-2.6(1.3)$ & $-2.9(1.2)$ & $-2.8(1.2)$ \\
\hline Loss Aversion & $4.0(3.0)$ & $4.4(3.3)$ & $4.0(3.2)$ & $3.9(3.4)$ & $3.6(3.2)$ \\
\hline
\end{tabular}

Note. FTND = Fagerström Test for Nicotine Dependence. ${ }^{a}$ Income recorded as $(0=$ USD $<10 k, 1=$ USD $10 k-15 k, 2=$ USD $15 k-<25 k$, $3=$ USD 25k-<35k, $4=$ USD 35k-<50k, $5=$ USD 50k-<75k, $6=$ USD 75k-<100k, $7=$ USD 100k-<150k, $8=$ USD 150k-<200k, $9=$ USD 200k+).

$\mathrm{b}$ Perceived quit efficacy coded as $(0=$ Not at all sure; $1=$ Moderately sure; $2=$ Sure; $3=$ Extremely sure). 


\subsection{Message Type}

A one-way ANOVA indicated a statistically significant effect of message type, $F_{1,507}=95.59$, $p<0.001$. This main effect primarily reflected significantly higher PME scores in the active message conditions compared to the control condition, $p$ values $<0.001$, Cohen's $d=1.88-2.48$ for active groups to control. The $2 \times 2$ ANOVA within active message conditions indicated a significant main effect of delay, $F_{1,407}=11.26, p<0.001$. This effect was characterized by higher PME scores for messages containing long-term compared to short-term outcomes, Cohen's $d=0.33$. The main effect of sign, $F_{1,407}=1.77, p=0.19$, and delay by sign interaction, $F_{1,407}=0.22, p=0.64$, were not statistically significant. Similar results were observed for individual PME items (Table 4; significant effect of Delay $p$ values $<0.02$ ).

Table 4. Main effect of delay on total PME scores and individual PME items.

\begin{tabular}{llllll}
\hline Variable & Control & Long-Gain & Long-Loss & Short-Gain & Short-Loss \\
\hline Total PME Score & $5.5(2.8)$ & $11.6(2.8)$ & $12.1(2.5)$ & $10.9(2.9)$ & $11.1(2.9)$ \\
Discourage from Smoking & $1.8(0.9)$ & $3.6(1.1)$ & $3.7(1.0)$ & $3.5(1.1)$ & $3.4(1.1)$ \\
Make Smoking Seem Unpleasant & $1.8(1.1)$ & $3.9(1.1)$ & $4.2(1.0)$ & $3.6(1.1)$ & $3.9(1.1)$ \\
Concerned about Health Consequences & $2.0(1.2)$ & $4.1(1.1)$ & $4.2(1.0)$ & $3.8(1.2)$ & $3.8(1.1)$ \\
\hline
\end{tabular}

\subsection{Individual Differences}

Table 5 contains standardized regression coefficients (effect sizes) for individual difference predictors of PME total scores and individual items for the active message conditions. The previously described association of long-term (versus short-term) messages with higher PME scores was again observed within these multivariable models (i.e., when controlling for demographic, nicotine dependence, and behavioral economic variables). Furthermore, because gains and losses are valued differently in the present and the future, we examined both gain and loss discounting. Although delay discounting and loss aversion did not covary, gain delay discounting and loss aversion showed a relationship with perceived message effectiveness. Specifically, participants with shallower delayed reward discounting and lower loss aversion reported higher PME total scores, $p$ values $<0.05$. Older participants and those with greater perceived quit efficacy also had higher PME total scores, $p<0.05$. These variables were each also associated with one or more individual item in the same direction with age significantly related to unpleasant and health consequence items, perceived efficacy significantly related to discourage and health consequence items, and low discount rates and loss aversion significantly related to the discourage item.

Table 5. Individual predictors of perceived message effectiveness.

\begin{tabular}{|c|c|c|c|c|c|c|c|c|}
\hline \multirow[t]{2}{*}{ Variable } & \multicolumn{2}{|c|}{ Total PME Score } & \multicolumn{2}{|c|}{ Discourage } & \multicolumn{2}{|c|}{ Unpleasant } & \multicolumn{2}{|c|}{ Health Consequence } \\
\hline & $\beta$ & $p$ & $\beta$ & $p$ & $\beta$ & $p$ & $\beta$ & $p$ \\
\hline \multicolumn{9}{|l|}{ Message Type } \\
\hline Long-Term Message & 0.14 & 0.004 & 0.10 & 0.046 & 0.12 & 0.015 & 0.15 & 0.003 \\
\hline Loss-Framed Message & -0.05 & 0.259 & 0.01 & 0.826 & -0.12 & 0.015 & -0.03 & 0.513 \\
\hline \multicolumn{9}{|l|}{ Individual Difference } \\
\hline Age & 0.13 & 0.016 & 0.09 & 0.091 & 0.12 & 0.029 & 0.12 & 0.021 \\
\hline Female & -0.06 & 0.261 & -0.05 & 0.348 & -0.08 & 0.140 & -0.02 & 0.629 \\
\hline Married & 0.08 & 0.129 & 0.03 & 0.528 & 0.08 & 0.112 & 0.09 & 0.098 \\
\hline White & -0.06 & 0.214 & -0.03 & 0.497 & -0.03 & 0.561 & -0.10 & 0.057 \\
\hline College Education & 0.01 & 0.793 & -0.01 & 0.853 & 0.04 & 0.379 & 0.00 & 0.976 \\
\hline Income & 0.02 & 0.721 & 0.07 & 0.170 & -0.06 & 0.264 & 0.04 & 0.490 \\
\hline Past Month Vaping & -0.06 & 0.245 & -0.05 & 0.321 & -0.04 & 0.413 & -0.06 & 0.240 \\
\hline Cigarettes/Day & -0.04 & 0.496 & -0.08 & 0.175 & -0.01 & 0.908 & -0.02 & 0.762 \\
\hline FTND & 0.02 & 0.757 & 0.07 & 0.248 & -0.01 & 0.835 & -0.01 & 0.904 \\
\hline Perceived Quit Efficacy & 0.16 & 0.002 & 0.17 & 0.001 & 0.09 & 0.067 & 0.15 & 0.003 \\
\hline Gain Discounting (Log) & -0.11 & 0.030 & -0.20 & $<0.001$ & -0.09 & 0.103 & -0.01 & 0.839 \\
\hline Loss Discounting (Log) & -0.06 & 0.258 & -0.03 & 0.515 & -0.07 & 0.198 & -0.05 & 0.337 \\
\hline Loss Aversion & -0.10 & 0.043 & -0.13 & 0.015 & -0.06 & 0.225 & -0.08 & 0.114 \\
\hline
\end{tabular}




\subsection{Congruency}

After random assignment to message exposure, approximately a quarter (23.3\%) of participants happened to be congruent with a message condition best suited for their behavioral economic profile. A $2 \times 4$ ANOVA indicated a significant main effect of this congruency, $F_{1,399}=4.14, p=0.04$, Cohen's $d=0.24$. This outcome reflected the higher total PME score for participants in a message condition congruent with their behavioral economic scores (Figure 1). The message type $\mathrm{x}$ congruency interaction was not statistically significant, $F_{1,399}=1.39, p=0.91$, providing insufficient support for differential effects of the matching association between message conditions. These outcomes were selective to congruency determined by the combination of delay discounting and loss aversion, because a significant prediction was not observed when congruency was determined based on delay discounting, $p=0.40$, or loss aversion, $p=0.10$, alone. Analysis by individual PME item indicated the same pattern of effect for the discourage (main effect of congruency, $p=0.02$, Cohen's $d=0.27$ ) and unpleasant ( $p=0.03$, Cohen's $d=0.25)$ items, but no significant congruency effect for the health consequences item, $p=0.40$.

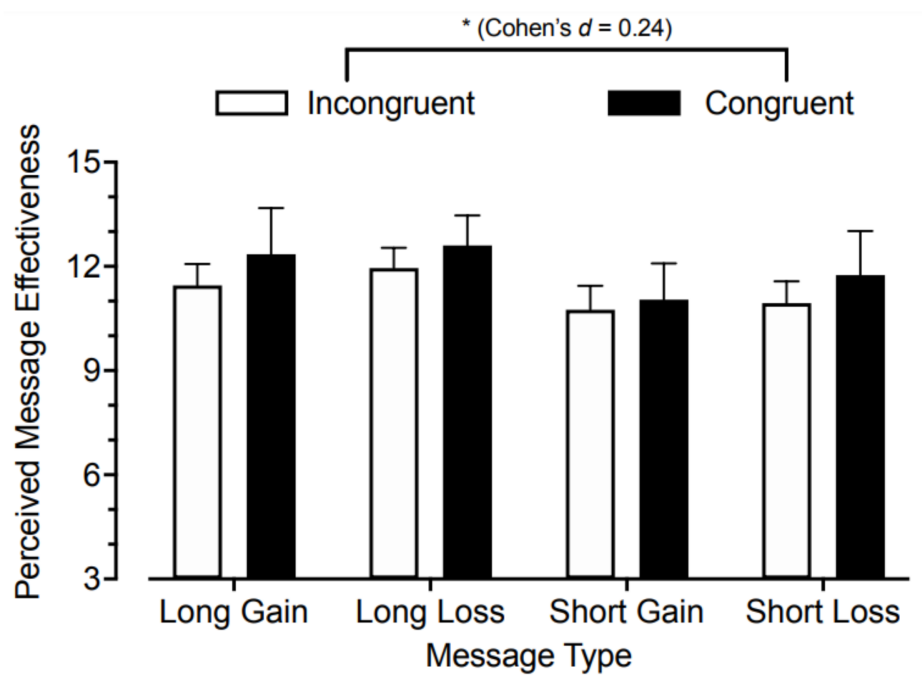

Figure 1. Total score perceived message effectiveness (PME) by message condition and behavioral economics matching. Presented are mean PME scores for each message condition. Error bars are $95 \%$ confidence intervals. Scores are divided by participants who were considered congruent versus incongruent with their randomly assigned message type based on behavioral economic delay discounting and loss aversion measures (see Data Analysis for details).

\section{Discussion}

The purpose of the present study was to evaluate whether an individual's loss aversion and delay discounting rates (i.e., behavioral economic characteristics) would influence the perceived effectiveness of anti-smoking messages through manipulation of the sign (gain versus loss) and delay (short-term vs. long-term) framing of those messages, particularly if message exposure was congruent with an individual's behavioral economic characteristics. Smoking cessation messages were feasibly delivered through an online crowdsourced platform with greater perceived effectiveness compared to control messages. Greater perceived message effectiveness was observed for messages that described long-term compared to short-term outcomes, regardless of sign. Participants showing less devaluation of future rewards by delay and greater similarity in their sensitivity to positive and negative outcomes (i.e., lower loss aversion) reported higher overall perceived message effectiveness. Finally, participants who saw a randomized message that best addressed their behavioral economic response profile reported higher perceived message effectiveness, although of a smaller effect size than individuals whose randomized message exposure was not congruent with their behavioral economic preferences. 


\subsection{Effects of Messages}

Participants who viewed experimental messages had higher PME scores than those exposed to the control condition. The evaluation of the main effects of these dimensions indicated no differential impact of gain or loss framing, but a statistically significant, small effect of long-term delay type. When examining group differences in sign alone, there was no difference between the gain and loss exposure groups. This finding may be attributable to the text-only nature of the messages. For example, Zhao and colleagues found that there was no framing effect when using text-only warnings, as this study did [19]. However, when examining the temporal context of the messages in the present study, there was a higher perceived effectiveness for those exposed to long-term messages compared to those exposed to short-term messages. This finding seems to counter temporal discounting research, which states that smokers tend to discount future outcomes more than non-smokers, and thus suggests a preference for short-term messages [24]. However, PME scores may be higher for long-term messages, because they indicate more severe consequences than short-term messages.

No interaction was observed by message type, indicating that the impact of sign did not differ by delay (or conversely that that impact of delay did not differ by sign). One reason for the lack of interaction may be attributable to the sign effect; this effect indicates that while the value of loss is discounted less over time, gains become increasingly less valuable in the future $[38,39]$. This effect can make it difficult to parse the effects of long-term messages. Another reason for the lack of interaction may come from the tense of the messages. In a study that examined the sign effect in past and future discounting, findings indicated that the tense in which the sign was presented has a multiplicative effect on the delay [40]. Specifically, the tense in which the sign of the message is conveyed can influence the amount of time one is willing to forego the consequence. In the current study, it is possible that the conditional tense of the messages-conveyed by words such as could and may - mitigated the value normally ascribed to potential health outcomes.

\subsection{Effects of Individual Differences}

Greater gain delay discounting and greater loss aversion were associated with lower PME scores. In terms of the gain delay discounting, this is an anticipated finding given that greater discounting of future gains has previously been associated with more severe nicotine dependence and reduced quit intentions/treatment responses [41,42]. However, higher rates of loss aversion related to reduced perceived message effectiveness is a novel finding. It may be that although the younger participants of the sample want to avoid potential losses, they have lower perceived personal health risks of smoking; this could explain why the messages are considered to be less compelling [43].

\subsection{Congruency}

Participants who were randomized to a message that was congruent with their behavioral economic profiles reported higher PME than individuals who were randomized to messages that were not congruent with their behavioral economic profiles, consistent with prospect theory. To date, no study has simultaneously tested how loss aversion and delay discounting rates of smokers can influence the perceived effectiveness of cigarette warning messages. We found that these behavioral economic differences influenced PME, which is a reliable measure of persuasiveness and has been associated with quit intentions and cessation behavior [44-47]. The current study offers evidence that tailored (congruent) messages improve PME, which could potentially lead to changes in smoking behavior. Through advances in technology, tailored messages are often used to target specific populations online. There is evidence that individualized public health communications have led to behavioral changes [48-50]. The tobacco industry and health agencies are already tailoring their respective messages using social media [51,52]. Further research should examine how these organizations might leverage behavioral economic profiles to increase the relevance of messages and the influence of individual behaviors. For example, a person 
who discounts the future at a high rate but has a low rate of loss aversion might find a message that states a more immediate, gain-focused consequence to be more effective than a message which conveys a long-term loss (as the currently proposed FDA warning messages are framed).

We are not aware of prior studies that have systematically evaluated loss aversion among smokers. The findings in this study indicate significant variation in the loss aversion rates of smokers. Instead of directing public health messages at the group level (i.e., smokers/nonsmokers), it may be advantageous to tailor messages according to individual-level loss aversion rates [53].

\section{Conclusions}

\subsection{Limitations and Future Directions}

At the time of writing, the ability of PME to predict behavioral change is debated; however, PME is a useful tool in determining whether subsequent behavioral studies are necessary $[44,47,54-56]$. Based on the findings, future studies should examine outcomes such as intention to quit or cessation. Additionally, messages in this study were only viewed once. Subsequent studies will rely on the Message Impact Framework to determine whether seeing congruent messages that are individually tailored multiple times might influence outcomes. Another limitation pertains to the inability to parse the magnitude of outcomes from the delay of outcomes, because the risk from smoking cigarettes is cumulative, becoming increasingly hazardous over time. Additionally, participants in the control group may be biased if they realized they were members of the control group based on messages unrelated to smoking.

\subsection{Conclusions}

Our findings highlight the influence of individual loss aversion and delay discounting. Rates on smokers' perceived message effectiveness of cigarette warning messages, messages congruent with behavioral economic profiles, increased PME scores. The results suggest that tailored public health messages about smoking may be more beneficial than current anti-smoking warnings, which generally convey long-term losses. Additional research is necessary to determine the clinical significance of these findings.

Supplementary Materials: The following are available online at https: / www.mdpi.com/article/10 .3390 /ijerph181910492/s1, Table S1: Ordinal logistic regression results for individual items.

Author Contributions: Conceptualization, H.L.T. and J.C.S.; Methodology, H.L.T., J.C.S., M.M., J.A.-M., E.C.D. and A.A.S.; Investigation, H.L.T.; Formal analysis, J.C.S.; Writing-original draft preparation, H.L.T. and J.C.S.; Writing-review and editing, M.M., J.A.-M., E.C.D. and A.A.S. All authors have read and agreed to the published version of the manuscript.

Funding: This research was funded by the National Institutes of Health and FDA Center for Tobacco Products, grant number U54CA229973 (Strasser), the National Cancer Institute, grant number K07CA218366 (Mercincavage), and by the National Institute on Drug Abuse, grant number T32DA007209.

Institutional Review Board Statement: Ethical review and approval were waived for this study, due to 45 CFR 46.104, category \#2 by the Institutional Review Board of the University of Pennsylvania (protocol code 834419 and 14 November 2019).

Informed Consent Statement: Informed consent was obtained from all subjects involved in the study.

Data Availability Statement: The data presented in this study are available on request from the corresponding author. The data are not publicly available in order to protect the privacy of participants.

Conflicts of Interest: The authors declare no conflict of interest. 


\section{References}

1. Byrne, S.; Greiner Safi, A.; Kemp, D.; Skurka, C.; Davydova, J.; Scolere, L.; Mathios, A.D.; Avery, R.J.; Dorf, M.C.; Steinhardt, J.; et al. Effects of Varying Color, Imagery, and Text of Cigarette Package Warning Labels among Socioeconomically Disadvantaged Middle School Youth and Adult Smokers. Health Commun. 2019, 34, 306-316. [CrossRef]

2. Beltramini, R.F. Perceived Believability of Warning Label Information Presented in Cigarette Advertising. J. Advert. 1988, 17, 26-32. [CrossRef]

3. Hammond, D.; Fong, G.T.; McDonald, P.W.; Brown, K.S.; Cameron, R. Showing leads to doing: Graphic cigarette warning labels are an effective public health policy. Eur. J. Public Health 2006, 16, 223-224. [CrossRef]

4. Mercincavage, M.; Burdge, J.; Lochbuehler, K.; Souprountchouk, V.; McCullough, A.A.; Strasser, A.A. Visual Attention Patterns Differ by Pictorial Health Warning Label Features. Tob. Regul. Sci. 2018, 4, 8-17. [CrossRef] [PubMed]

5. Kahneman, D.; Tversky, A. Prospect theory: An analysis of decision under risk. Econom. J. Econom. Soc. 1979, 47, $263-291$. [CrossRef]

6. Tversky, A.; Kahneman, D. Loss Aversion in Riskless Choice: A Reference-Dependent Model. Q. J. Econ. 1991, $106,1039-1061$. [CrossRef]

7. Camerer, C. Prospect theory in the wild: Evidence from the field. In Choices, Values, and Frames; Kahneman, D., Tversky, A., Eds.; Cambridge University Press: Cambridge, UK, 2001; pp. 288-300.

8. Novemsky, N.; Kahneman, D. The boundaries of loss aversion. J. Mark. Res. 2005, 42, 119-128. [CrossRef]

9. Barberis, N.C. Thirty years of prospect theory in economics: A review and assessment. J. Econ. Perspect. 2013, 27, 173-196. [CrossRef]

10. Toll, B.A.; Rojewski, A.M.; Duncan, L.R.; Latimer-Cheung, A.E.; Fucito, L.M.; Boyer, J.L.; O’Malley, S.S.; Salovey, P.; Herbst, R.S. "Quitting smoking will benefit your health": The evolution of clinician messaging to encourage tobacco cessation. Clin. Cancer Res. 2014, 20, 301-309. [CrossRef] [PubMed]

11. Steward, W.T.; Schneider, T.R.; Pizarro, J.; Salovey, P. Need for Cognition Moderates Responses to Framed Smoking-Cessation Messages 1. J. Appl. Soc. Psychol. 2003, 33, 2439-2464. [CrossRef]

12. Schneider, T.R.; Salovey, P.; Pallonen, U.; Mundorf, N.; Smith, N.F.; Steward, W.T. Visual and auditory message framing effects on tobacco smoking 1. J. Appl. Soc. Psychol. 2001, 31, 667-682. [CrossRef]

13. Gallagher, K.M.; Updegraff, J.A. Health message framing effects on attitudes, intentions, and behavior: A meta-analytic review. Ann. Behav. Med. 2012, 43, 101-116. [CrossRef] [PubMed]

14. Mays, D.; Turner, M.M.; Zhao, X.; Evans, W.D.; Luta, G.; Tercyak, K.P. Framing Pictorial Cigarette Warning Labels to Motivate Young Smokers to Quit. Nicotine Tob. Res. 2015, 17, 769-775. [CrossRef] [PubMed]

15. Bansal-Travers, M.; Hammond, D.; Smith, P.; Cummings, K.M. The impact of cigarette pack design, descriptors, and warning labels on risk perception in the U.S. Am. J. Prev. Med. 2011, 40, 674-682. [CrossRef] [PubMed]

16. Nan, X.; Zhao, X.; Yang, B.; Iles, I. Effectiveness of cigarette warning labels: Examining the impact of graphics, message framing, and temporal framing. Health Commun. 2015, 30, 81-89. [CrossRef] [PubMed]

17. Romanowich, P.; Lamb, R.J. The effect of framing incentives as either losses or gains with contingency management for smoking cessation. Addict. Behav. 2013, 38, 2084-2088. [CrossRef] [PubMed]

18. Zhao, X.; Peterson, E. Effects of Temporal Framing on Response to Antismoking Messages: The Mediating Role of Perceived Relevance. J. Health Commun. 2017, 22, 37-44. [CrossRef]

19. Zhao, X.; Nan, X.; Iles, I.A.; Yang, B. Temporal framing and consideration of future consequences: Effects on smokers' and at-risk nonsmokers' responses to cigarette health warnings. Health Commun. 2015, 30, 175-185. [CrossRef] [PubMed]

20. Ainslie, G. Specious reward: A behavioral theory of impulsiveness and impulse control. Psychol. Bull. 1975, 82, 463-496. [CrossRef]

21. Chung, S.H.; Herrnstein, R.J. Choice and delay of reinforcement. J. Exp. Anal. Behav. 1967, 10, 67-74. [CrossRef]

22. Rachlin, H.; Green, L. Commitment, choice and self-control. J. Exp. Anal. Behav. 1972, 17, 15-22. [CrossRef] [PubMed]

23. Amlung, M.; Vedelago, L.; Acker, J.; Balodis, I.; MacKillop, J. Steep delay discounting and addictive behavior: A meta-analysis of continuous associations. Addiction 2017, 112, 51-62. [CrossRef] [PubMed]

24. Baker, F.; Johnson, M.W.; Bickel, W.K. Delay discounting in current and never-before cigarette smokers: Similarities and differences across commodity, sign, and magnitude. J. Abnorm. Psychol. 2003, 112, 382-392. [CrossRef] [PubMed]

25. Bickel, W.K.; Marsch, L.A. Toward a behavioral economic understanding of drug dependence: Delay discounting processes. Addiction 2001, 96, 73-86. [CrossRef]

26. Mollen, S.; Engelen, S.; Kessels, L.T.; van den Putte, B. Short and Sweet: The Persuasive Effects of Message Framing and Temporal Context in Antismoking Warning Labels. J. Health Commun. 2017, 22, 20-28. [CrossRef] [PubMed]

27. Strickland, J.C.; Beckmann, J.S.; Rush, C.R.; Stoops, W.W. A pilot study of loss aversion for drug and non-drug commodities in cocaine users. Drug Alcohol Depend. 2017, 180, 223-226. [CrossRef] [PubMed]

28. Ahn, W.Y.; Vasilev, G.; Lee, S.H.; Busemeyer, J.R.; Kruschke, J.K.; Bechara, A.; Vassileva, J. Decision-making in stimulant and opiate addicts in protracted abstinence: Evidence from computational modeling with pure users. Front. Psychol. $2014,5,849$. [CrossRef] [PubMed] 
29. Hulka, L.M.; Eisenegger, C.; Preller, K.H.; Vonmoos, M.; Jenni, D.; Bendrick, K.; Baumgartner, M.R.; Seifritz, E.; Quednow, B.B. Altered social and non-social decision-making in recreational and dependent cocaine users. Psychol. Med. 2014, 44, 1015-1028. [CrossRef] [PubMed]

30. Fridberg, D.J.; Queller, S.; Ahn, W.Y.; Kim, W.; Bishara, A.J.; Busemeyer, J.R.; Porrino, L.; Stout, J.C. Cognitive Mechanisms Underlying Risky Decision-Making in Chronic Cannabis Users. J. Math. Psychol. 2010, 54, 28-38. [CrossRef]

31. Stoet, G. PsyToolkit: A software package for programming psychological experiments using Linux. Behav. Res. Methods 2010, 42, 1096-1104. [CrossRef]

32. Heatherton, T.F.; Kozlowski, L.T.; Frecker, R.C.; Fagerstrom, K.O. The Fagerstrom Test for Nicotine Dependence: A revision of the Fagerstrom Tolerance Questionnaire. Br. J. Addict. 1991, 86, 1119-1127. [CrossRef] [PubMed]

33. Takahashi, H.; Fujie, S.; Camerer, C.; Arakawa, R.; Takano, H.; Kodaka, F.; Matsui, H.; Ideno, T.; Okubo, S.; Takemura, K.; et al. Norepinephrine in the brain is associated with aversion to financial loss. Mol. Psychiatry 2013, 18, 3-4. [CrossRef]

34. Takeuchi, H.; Kawada, R.; Tsurumi, K.; Yokoyama, N.; Takemura, A.; Murao, T.; Murai, T.; Takahashi, H. Heterogeneity of Loss Aversion in Pathological Gambling. J. Gambl. Stud. 2016, 32, 1143-1154. [CrossRef]

35. Koffarnus, M.N.; Bickel, W.K. A 5-trial adjusting delay discounting task: Accurate discount rates in less than one minute. Exp. Clin. Psychopharmacol. 2014, 22, 222-228. [CrossRef]

36. Baig, S.A.; Noar, S.M.; Gottfredson, N.C.; Boynton, M.H.; Ribisl, K.M.; Brewer, N.T. UNC Perceived Message Effectiveness: Validation of a Brief Scale. Ann. Behav. Med. 2019, 53, 732-742. [CrossRef]

37. Love, J.; Selker, R.; Marsman, M.; Jamil, T.; Dropmann, D.; Verhagen, J.; Ly, A.; Gronau, Q.F.; Šmíra, M.; Epskamp, S.; et al. JASP: Graphical statistical software for common statistical designs. J. Stat. Softw. 2019, 88, 1-7. [CrossRef]

38. Thaler, R. Some empirical evidence on dynamic inconsistency. Econ. Lett. 1981, 8, 201-207. [CrossRef]

39. Baucells, M.; Bellezza, S. Temporal profiles of instant utility during anticipation, event, and recall. Manag. Sci. 2017, 63, 729-748. [CrossRef]

40. Molouki, S.; Hardisty, D.J.; Caruso, E.M. The Sign Effect in Past and Future Discounting. Psychol. Sci. 2019, 30, 1674-1695. [CrossRef]

41. Athamneh, L.N.; Stein, J.S.; Bickel, W.K. Will delay discounting predict intention to quit smoking? Exp. Clin. Psychopharmacol. 2017, 25, 273-280. [CrossRef] [PubMed]

42. Amlung, M.; MacKillop, J. Clarifying the relationship between impulsive delay discounting and nicotine dependence. Psychol. Addict. Behav. 2014, 28, 761. [CrossRef] [PubMed]

43. Halpern-Felsher, B.L.; Biehl, M.; Kropp, R.Y.; Rubinstein, M.L. Perceived risks and benefits of smoking: Differences among adolescents with different smoking experiences and intentions. Prev. Med. 2004, 39, 559-567. [CrossRef] [PubMed]

44. Cappella, J.N. Perceived Message Effectiveness Meets the Requirements of a Reliable, Valid, and Efficient Measure of Persuasiveness. J. Commun. 2018, 68, 994-997. [CrossRef]

45. Noar, S.M.; Rohde, J.A.; Prentice-Dunn, H.; Kresovich, A.; Hall, M.G.; Brewer, N.T. Evaluating the actual and perceived effectiveness of e-cigarette prevention advertisements among adolescents. Addict. Behav. 2020, 109, 106473. [CrossRef] [PubMed]

46. Bigsby, E.; Cappella, J.N.; Seitz, H.H. Efficiently and Effectively Evaluating Public Service Announcements: Additional Evidence for the Utility of Perceived Effectiveness. Commun. Monogr. 2013, 80, 1-23. [CrossRef] [PubMed]

47. Davis, K.C.; Duke, J.; Shafer, P.; Patel, D.; Rodes, R.; Beistle, D. Perceived Effectiveness of Antismoking Ads and Association with Quit Attempts Among Smokers: Evidence from the Tips from Former Smokers Campaign. Health Commun. 2017, 32, 931-938. [CrossRef]

48. Krebs, P.; Prochaska, J.O.; Rossi, J.S. A meta-analysis of computer-tailored interventions for health behavior change. Prev. Med. 2010, 51, 214-221. [CrossRef]

49. Ryan, K.; Dockray, S.; Linehan, C. A systematic review of tailored eHealth interventions for weight loss. Digit. Health 2019, 5, 2055207619826685. [CrossRef]

50. Sahin, C.; Courtney, K.L.; Naylor, P.J.; Rhodes, R.E. Tailored mobile text messaging interventions targeting type 2 diabetes self-management: A systematic review and a meta-analysis. Digit. Health 2019, 5, 2055207619845279. [CrossRef]

51. Escobedo, P.; Tsai, K.-Y.; Majmundar, A.; Allem, J.-P.; Soto, D.W.; Pattarroyo, M.; Unger, J.B.; Cruz, T.B. Do tobacco industry websites target content to specific demographic groups? Drug Alcohol Depend. 2020, 208, 107852. [CrossRef]

52. Skurka, C.; Wheldon, C.W.; Eng, N. Targeted truth: An experiment testing the efficacy of counterindustry tobacco advertisements targeted to Black individuals and sexual and gender minority individuals. Nicotine Tob. Res. 2021, 23, 1542-1550. [CrossRef] [PubMed]

53. Green, L.; Myerson, J. On the Complexity of Discounting, Choice Situations, and People. Perspect. Behav. Sci. 2019, 42, 433-443. [CrossRef] [PubMed]

54. Noar, S.M.; Barker, J.; Bell, T.; Yzer, M. Does Perceived Message Effectiveness Predict the Actual Effectiveness of Tobacco Education Messages? A Systematic Review and Meta-Analysis. Health Commun. 2020, 35, 148-157. [CrossRef]

55. Brennan, E.; Durkin, S.J.; Wakefield, M.A.; Kashima, Y. Talking about antismoking campaigns: What do smokers talk about, and how does talk influence campaign effectiveness? J. Health Commun. 2016, 21, 33-45. [CrossRef]

56. O'Keefe, D.J. Message pretesting using assessments of expected or perceived persuasiveness: Evidence about diagnosticity of relative actual persuasiveness. J. Commun. 2018, 68, 120-142. [CrossRef] 